\title{
Modelling the impact of Artificial Intelligence on the labour market in Czechia
}

\begin{abstract}
This article describes an original model developed in the Technology Centre CAS for the estimation of the impact of Artificial Intelligence (AI) on the labour market in Czechia. On the contrary to the previous estimates, this model is based on the comparison of projected future technical capabilities of AI with a mix of capabilities needed in different job categories. Both the importance and the level of capabilities are taken into account in order to assess the impact of AI on jobs in three different time horizons. Based on the model calculations, it can be expected that on the five-year horizon the AI will be able to replace more than $50 \%$ of the required capabilities in $11 \%$ of the occupations. On the thirty-year horizon, AI can replace over $50 \%$ of capabilities in the vast majority of the current professions. At the same time, new professions will continuously emerge, though they will place different demands on their performers and will require different skills and capabilities in comparison to current professions. The model and its results may be effectively used for efficient adaptation of education, lifelong learning and retraining to the changing nature of work, and related new demand for workers' capabilities.
\end{abstract}

KEYWORDS: Artificial Intelligence; labour market; economic modelling; economic impact

RECEIVED 14 May 2020; ACCEPTED 20 April 2021.

\section{INTRODUCTION}

The contemporary digital technological revolution is caused by several synergic factors. The economic availability of advanced information technologies enables their massive deployment in the form of new machines and tools (programmable manipulators, cobots, wide range of software tools). They partially replace routine human work and, in cooperation with humans, increase the productivity and the quality of work. The interconnectivity and the interoperability of information systems both vertically and across sectors open up new opportunities in the organization and optimization of logistics, production, and in the entire production chain.

The development of artificial intelligence (AI) methods and applications extends the spectrum of assisted and replaced human activities by not entirely routine, but (at least for now) well-defined and algorithmized activities within the so-called white collar professions. Thus, the development of AI methods and applications completes the process of the so-called 4th Industrial Revolution. It raises questions about the further coexistence of "smart" machines and tools with humans and their social and economic impact. A number of studies and documents have addressed this issue at national as well as global levels in the last decade.

The objective of our research was to build on previous foreign studies on the impact of AI and automation on the labour market, and to show the impact that the use of AI can have on the labour market in Czechia. In connection with previous studies, the analytical team of the Technology Centre CAS prepared an original model of the AI impact on the labour market, which is specifically focused on the situation and data sources in the Czech Republic. On the contrary to the previous estimates, our model is based on the comparison of projected future technical capabilities of AI with a mix of capabilities needed in different job categories. Both the importance and the level of capabilities are taken into account in order to assess the impact of AI on jobs in three different time horizons. The model provides an estimate of the technological potential of human labour substitutability by AI for individual groups of professions at 5-, 15-, and 30-year horizons.

The output of the model is a description of the expected state of the labour market in Czechia in the above data horizons, which is the basis for strategic planning and formulation of development and regulatory measures in the field of public policy. The results

1 Technology Centre CAS, Prague, Czech Republic 
of the research were thus directly used, e.g., in formulating the government's National Artificial Intelligence Strategy of the Czech Republic (MPO 2019).

In this article, we first summarize the approaches described in the literature to assess the impact of AI and automation on the labour market. Then we present our original model specifically focused on the situation in the Czech Republic, and its outputs. In the end, we focus on the generalization of outputs of our and other models and the resulting recommendations for public policy.

\section{IMPACT MODELLING}

\section{Approaches described in the literature}

Based on a review of previous studies on the impact of AI and automation on the labour market, three basic approaches can be identified. The first approach, based on an expert estimate of the potential for automating individual occupations (occupation-based approach), was used by Frey and Osborne (2013). During a workshop the expert panel reviewed 70 occupational categories where the experts identified the probability of automation on the basis of description of the performed activities. Based on these expert estimates, the authors have identified a set of activities that are likely to be substitutable with technologies. Subsequently, using a learning algorithm, they determined the probability of automation for 702 occupational categories in the US labour market. The results of the study by Frey and Osborn (2013) were reproduced in follow-up national studies, such as the study by Bonin (2015) for Germany or Deloitte (2018) for the Czech Republic.

The second approach estimates the likelihood of automating individual occupations based on an estimate of the capacity for automation of actions performed in each profession (task-based approach). The initial consideration for this approach is that, as a rule, not complete occupations, but rather partial individual actions are fully automated. This approach was used in the OECD study (2016), which estimated the impact of digitization on different occupational categories in 21 OECD countries. Unlike Frey and Osborn (2013), the OECD authors do not work with expert estimates of the likelihood of automating each occupation (and the derived probabilities of automating the activities performed in these occupations); however, they use Programme for the International Assessment of Adult Competencies (PIAAC) data to identify tasks performed in each occupation. By combining the likelihood of automating the various occupations set out in Frey and Osborn's (2013) study with detailed information on the activities performed in occupations, they get an estimate of the relationship between performed working tasks and the probability of automation of a particular occupation in the United States. This relationship was subsequently used to recalculate occupation automation probabilities in 21 other OECD countries as well, whereas the use of PIAAC results takes into account the differences between countries in working tasks performed in each occupation.

The third approach is to estimate the potential for automation of sub-activities performed in individual occupations (activitybased approach), which was used by the McKinsey Global Institute (MGI 2017). This approach is based on the decomposition of individual occupational categories (according to the Occupational Information Network's O*Net database classification) to a set of working activities (specifically over 2000 activities). Subsequently, the potential of automation in relation to the technological capabilities achieved in the present and in future years was identified for each working activity making use of a keyword system and trained machine learning algorithms. These results were subsequently used for the recalculation of impacts on individual occupational categories and consequently on the labour market in individual sectors of the economy. This approach has been applied to 46 countries, which collectively represent $80 \%$ of the global production. For example, the MGI study (2017) points out that the current potential for automating individual activities (and occupations) is not related to wages, as there are well-paid jobs with a high potential for automation and, on the contrary, low-wage jobs with a low automation potential.

In connection with previous studies, the analytical team of the Technology Centre CAS prepared an original model of the AI impact on the labour market, which is specifically focused on the situation and data sources in the Czech Republic. The model provides an estimate of the technological potential of human labour substitutability by AI for individual groups of professions at 5-, $15-$, and 30-year horizons. 


\section{Sciendo}

\section{Methodology of the capability-based model}

The approach used in the model builds on the above cited studies and focuses on estimating the potential for automation by assessing the level of capabilities required for the performance of individual occupations and of the time horizon when the required levels of capabilities will be achieved by technology (capability-based approach). The model mainly follows the approach of MGI (2017), but does not work with activities carried out in individual occupations, but directly with information about the capabilities needed to perform the job. This approach makes possible to assess which skills in each occupation will be attained at the necessary level by technology, and simultaneously the horizon for achieving such a level of technology. This information can be used, e.g., to prepare retraining strategies or education systems.

The model is based on two primary data sources. The first starting point is the $\mathrm{O}^{*} \mathrm{Net}$ database providing information about the abilities required to perform each profession. There are 967 occupational categories in the $\mathrm{O}^{*} \mathrm{Net}$ database broken down by the Standard Occupational Classification (SOC). The second starting point is the MGI database on capabilities that can be automated (i.e., replaced by technology) over time. For each of the capabilities in the MGI database two time horizons are set for technologies - a time horizon to reach a moderate level of capability and a time horizon to attain a high level of capability.

These primary resources were further transformed in several successive steps. In the first step, a transformation matrix was created between the categories of ability used in $\mathrm{O}^{*} \mathrm{Net}$ and the categories of capability according to MGI. In the second step, a transformation matrix was created for linking the detailed list of occupational categories used in the $\mathrm{O}^{*}$ Net database $\left(\mathrm{O}^{*} \mathrm{Net}\right.$ SOC code) to six-digit SOC categories (SOC code 2010). The result was a list of 820 SOC occupational categories with associated values of significance and skill level required to perform the occupation. In the third step, the transformation matrix of the US Bureau of Labor Statistics was used to conversion between occupational categories according to the SOC code 2010 and the ISCO-08 code (according to the International Standard Classification of Occupations). Using this matrix, the values of significance and skill level required to perform occupations were converted from six-digit SOC categories to four-digit ISCO categories. The result was a list of 431 ISCO occupational categories with associated values of significance and skill levels for each occupation.

In the fourth step, four time horizons were set to assess the potential of AI technology to achieve each of the capabilities: up to 5 years, 6-15 years, 16-30 years, and over 30 years. The time horizon takes into account 1) time to achieve technical capabilities to replace certain activities and 2) time from achieving technical capabilities to the development of a functional solution. On the contrary, economic advantage is not taken into account in the time horizon, i.e., the point when technology costs and labour costs are balanced, and the time from commercial solution to wide use, including technology acceptance in society. Information on the expected technological maturity to achieve the average level and high level of capabilities was taken from the MGI study. The result was an overview of 16 capabilities with fixed horizons at which technology reaches average and high levels of capability.

In the fifth step, the outputs from steps three and four were linked, giving each ISCO occupation category an overview of the capabilities that AI technologies can replace in each time horizon. In determining the time horizon of substitutability, the level of capabilities required for performing the occupation and the time expected for achieving the same level using technology were taken into account. For example, if a high level of competence is required for a given occupation, and the technology reaches only an average level of ability within a given time horizon, it means that the ability will not be substitutable in that time horizon.

In the sixth step, the importance of the individual capabilities for the performance of occupation was taken into account. For each ISCO occupation category and each time horizon, the proportion of skills that can be achieved by AI technologies at the same or higher quality (so-called substitutable capabilities) has been determined. This share was determined as the ratio of the sum of the significance of the substitutable capabilities and the sum of the significance of all the capabilities needed to perform the occupation. The sum of the significance of substitutable capabilities was calculated cumulatively for each time horizon. As a result, the share of substitutable capabilities was set for each occupational category and each time horizon.

The outcomes of the model thus include an overview of the skills required for the performance of individual occupations, an assessment of the potential for the technical replacement of individual skills in the monitored time horizons, and a determination of the share of substitutable skills for individual occupations in the monitored time horizons. 
Tab. 1: Overview of the observed skills crucial to perform the individual occupations

\begin{tabular}{|c|c|c|}
\hline Skill area & Skills & Skills description \\
\hline $\begin{array}{l}\text { Sensory } \\
\text { perception }\end{array}$ & Sensory perception & $\begin{array}{l}\text { Ability to respond to signals by movement, to see objects at a close range and at a } \\
\text { distance, to see objects in low light, to recognize colours and their hues, to recognize } \\
\text { distances, differences in sounds, differences in the direction of sound, to recognize } \\
\text { sound in a disruptive environment. }\end{array}$ \\
\hline \multirow[t]{8}{*}{$\begin{array}{l}\text { Cognitive } \\
\text { capabilities }\end{array}$} & $\begin{array}{l}\text { Recognizing existing patterns } \\
\text { and categories (supervised } \\
\text { learning) }\end{array}$ & $\begin{array}{l}\text { Ability to recognize a problem, derive a meaning from known categories of stimuli, } \\
\text { to identify known patterns (object, sound, image) in a disruptive environment, to } \\
\text { compare similarities and differences, to estimate the form of patterns (shapes, } \\
\text { objects, ...) when a part of them is rearranged. }\end{array}$ \\
\hline & $\begin{array}{l}\text { Generating novel patterns/ } \\
\text { categories }\end{array}$ & $\begin{array}{l}\text { Ability to develop new ideas (the number is of importance, not originality, quality, or } \\
\text { correctness). }\end{array}$ \\
\hline & $\begin{array}{l}\text { Logical reasoning and problem } \\
\text { solving }\end{array}$ & $\begin{array}{l}\text { Ability to apply general rules to specific problems and to formulate answers that } \\
\text { make sense, to combine information that gives rise to general rules or conclusions (it } \\
\text { includes finding a relationship between seemingly unrelated events), to determine } \\
\text { correct mathematical methods or formulas for solving a problem. }\end{array}$ \\
\hline & Optimization and planning & $\begin{array}{l}\text { Ability to create or to use different sets of rules for combining or grouping objects in } \\
\text { various ways - add, subtract, multiply, or divide in a fast and a correct way. }\end{array}$ \\
\hline & Creativity & $\begin{array}{l}\text { Ability to develop unusual and clever ideas about a given topic or situation, or to } \\
\text { develop creative ways to solve a problem. }\end{array}$ \\
\hline & Information retrieval & $\begin{array}{l}\text { Ability to organize objects or actions in a certain order or pattern based on a } \\
\text { particular rule or on a set of rules (e.g., patterns of numbers, letters, words, images, } \\
\text { mathematical operations), ability to remember information such as words, numbers, } \\
\text { images, and processes. }\end{array}$ \\
\hline & $\begin{array}{l}\text { Coordination with multiple } \\
\text { agents }\end{array}$ & $\begin{array}{l}\text { Ability to focus on a certain task for a certain amount of time without distraction, to } \\
\text { switch between two or more activities or sources of information (e.g., speech, sounds, } \\
\text { touches, or other sources). }\end{array}$ \\
\hline & $\begin{array}{l}\text { Output articulation/ } \\
\text { presentation }\end{array}$ & Ability to deliver information and thoughts in writing. \\
\hline \multirow{2}{*}{$\begin{array}{l}\text { Natural } \\
\text { language } \\
\text { processing }\end{array}$} & Natural language generation & Ability to deliver information and thoughts in spoken word. \\
\hline & Natural language understanding & $\begin{array}{l}\text { Ability to listen and to understand information and thoughts presented in spoken } \\
\text { words and sentences, to read and to understand information and thoughts presented } \\
\text { in written text. }\end{array}$ \\
\hline $\begin{array}{l}\text { Social and } \\
\text { emotional } \\
\text { capabilities }\end{array}$ & $\begin{array}{l}\text { Social and emotional sensing, } \\
\text { understanding, and expression }\end{array}$ & $\begin{array}{l}\text { Ability to identify and to understand the speech of other person and to speak clearly } \\
\text { so others can understand emotional nuances }\end{array}$ \\
\hline \multirow[t]{4}{*}{$\begin{array}{l}\text { Physical } \\
\text { capabilities }\end{array}$} & Fine motor skills & $\begin{array}{l}\text { Ability to carry out coordinated finger movements of one or both hands to grab, to } \\
\text { manipulate or to assemble tiny objects, to set quickly and repeatedly machine or } \\
\text { vehicle controls to defined positions, to carry out quick and repetitive finger, hand, } \\
\text { and wrist motions. }\end{array}$ \\
\hline & Gross motor skills & $\begin{array}{l}\text { Ability to generate maximal muscle strength to lift, push, pull, or move objects, to } \\
\text { bend, stretch, turn, or reach the body, arms, or legs, and to coordinate arm, body, and } \\
\text { leg movement. }\end{array}$ \\
\hline & Navigation & $\begin{array}{l}\text { Ability to identify own location in the environment; determination of relative position } \\
\text { of objects }\end{array}$ \\
\hline & Mobility & Ability to physically move for a long time. \\
\hline
\end{tabular}

Source: TC CAS with the use of MGI (2017). 


\section{Skills required for the performance of occupations}

The first type of results that has been achieved in the design of the model and its individual parameters is an overview of the skills required for the performance of each profession. This information is based primarily on the $\mathrm{O}^{*} \mathrm{Net}$ source database and it is reclassified for the occupational categories used in Czechia (CZ-ISCO) and 16 skill groups (shown in Table 1). Each occupation requires a specific mix of skills of different levels. At the same time, each skill has specific significance for performing different occupations.

The authors decided to use the $\mathrm{O}^{*}$ Net database instead of the national Central Competence Database (CCD, part of the National System of Occupations) administered by the Ministry of Labour and Social Affairs, mainly for three reasons. First, the $\mathrm{O}^{*}$ Net database contains a more detailed breakdown of skills without reference to the professional skills and knowledge required in the individual professions. Secondly, the $\mathrm{O}^{*}$ Net database makes it possible to assess not only the skill level required for the occupation but also the importance of the skills required to practice the profession, as opposed to CCD. Thirdly, data values in the $\mathrm{O}^{*}$ Net database are of a continuous nature, while in CCD they are discrete. For analytical purposes, the $\mathrm{O}^{*} \mathrm{Net}$ database seemed more appropriate.

Sensory capabilities are particularly important for the following occupational categories (aggregated along 2-digit CZ-ISCO codes):

- Drivers and mobile plant operators (83)

- Protective services workers (54)

- Market-oriented skilled forestry, fishery, and hunting workers (62)

- Electrical and electronic trades workers (74)

- Market-oriented skilled agricultural workers (61)

However, each of these occupational categories requires a different combination of additional skills. While physical skills (especially navigation) are important for drivers and mobile plant operators (83), cognitive abilities such as the coordination capability in a multifactor environment or logical reasoning and problem solving, are important for protective service workers (54), including firefighters and police. Also within the individual occupational groups, according to 2-digit CZ-ISCO codes, some variability in the structure of the required skills can be found. An example of this might be the protective service workers (54), where navigation skills are much more important for the firefighters (5411) than for security guards (5414) or prison guards (5413).

Cognitive capabilities are important in the whole spectrum of occupations, and especially for managers and specialists. Profoundly important are the cognitive skills for the following occupational groups:

- Science and engineering professionals (21)

- Health professionals (22)

- Administrative and commercial managers (12)

- Production and specialized services managers (13)

- Chief executives, senior officials, and legislators (11)

However, the internal structure of cognitive capabilities required to perform a profession varies significantly between categories. Highly important skills for managers and specialists involve the ability to present clearly results, and the ability to recognize existing patterns of phenomena and their categorization. These skills are highly relevant to all occupations in the group of executives and specialists with the exception of visual artists (2651). Greater differences in the significance of individual cognitive skills for managers and specialists are evident in skills such as information gathering and the coordination capability in a multifactor environment. While the information gathering is a highly relevant skill for the scientific and teaching professions, it is of little importance for artistic professions and software developers. In addition to managers and specialists, cognitive skills are also relevant to selected professions from other occupational groups. Examples are pilots and air traffic controllers, customs and police officers, or church staff.

Similar to cognitive capabilities, the language capabilities are important in a wide range of professions in the group of managers and specialists. Particular professions for which language skills are highly important include lawyers and prosecutors, general practitioners, social and health service managers, teachers (at all school grades), or church staff. In terms of occupational groups, language capabilities were assessed as highly relevant to the following occupational categories:

- Teaching professionals (23)

- Chief executives, senior officials, and legislators (11)

- Health professionals (22) 
Tab. 2: Time horizon to achieve suitable skill levels by technology

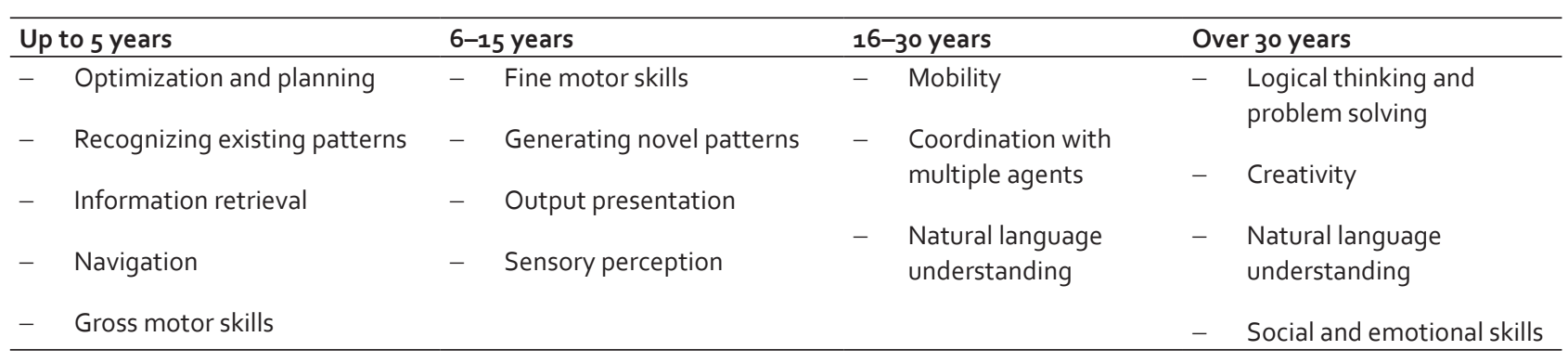

Source: TC CAS with the use of MGI (2017).

- Administrative and commercial managers (12)

- Production and specialized services managers (13)

Social and emotional capabilities are particularly important for decision makers, for selected professionals (especially in health services and teaching), and for some other occupations such as vendors, police officers, stewards, guides, and others. In terms of occupational groups, social and emotional capabilities are most important for the following occupational categories:

- Chief executives, senior officials, and legislators (11)

- Teaching professionals (23)

- Administrative and commercial managers (12)

- Hospitality, retail, and other services managers (14)

- Health professionals (22)

As expected, physical capabilities are particularly important for manual occupations (groups 6-9 according to CZ-ISCO). However, the variability in the significance of individual physical capabilities is relatively broad within manual occupations. While fine motor skills are important for most manual occupations (with the exception of street vendors), the importance of capabilities such as gross motor skills, navigation and mobility varies considerably within the manual occupation class. For example, navigation capabilities that are highly relevant to drivers, pilots, or courier occupations are quite insignificant for cleaning jobs, food preparation, or traditional crafts. Among other occupations, physical capabilities and primarily fine motor skills are also important for the health occupations. In terms of occupational groups, physical capabilities are most important for the following occupational categories:

- Subsistence farmers, fishers, hunters, and gatherers (63)

- Agricultural, forestry, and fishery labourers (92)

- Market-oriented skilled forestry, fishery, and hunting workers (62)

- Protective services workers (54)

- Business and administration associate professionals (83)

- Building and related trades workers, excluding electricians (71)

- Labourers in mining, construction, manufacturing, and transport (93)

\section{Potential for replacing skills}

The starting point for assessing the potential of technologies to replace the various skills required for the performance of a particular occupation is the MGI (2017) study, which, based on expert judgment, identifies time horizons in which technologies will achieve the appropriate average or high level of skills compared to human skills.

From the estimate, it is evident that for the five skills, the technology already reaches the level corresponding to the highest quartile of human skills, namely, it is the capability to recognize existing patterns and categories, the capability to optimize and plan, 
Fig. 1: Share of substitutable skills in a 5-year time frame

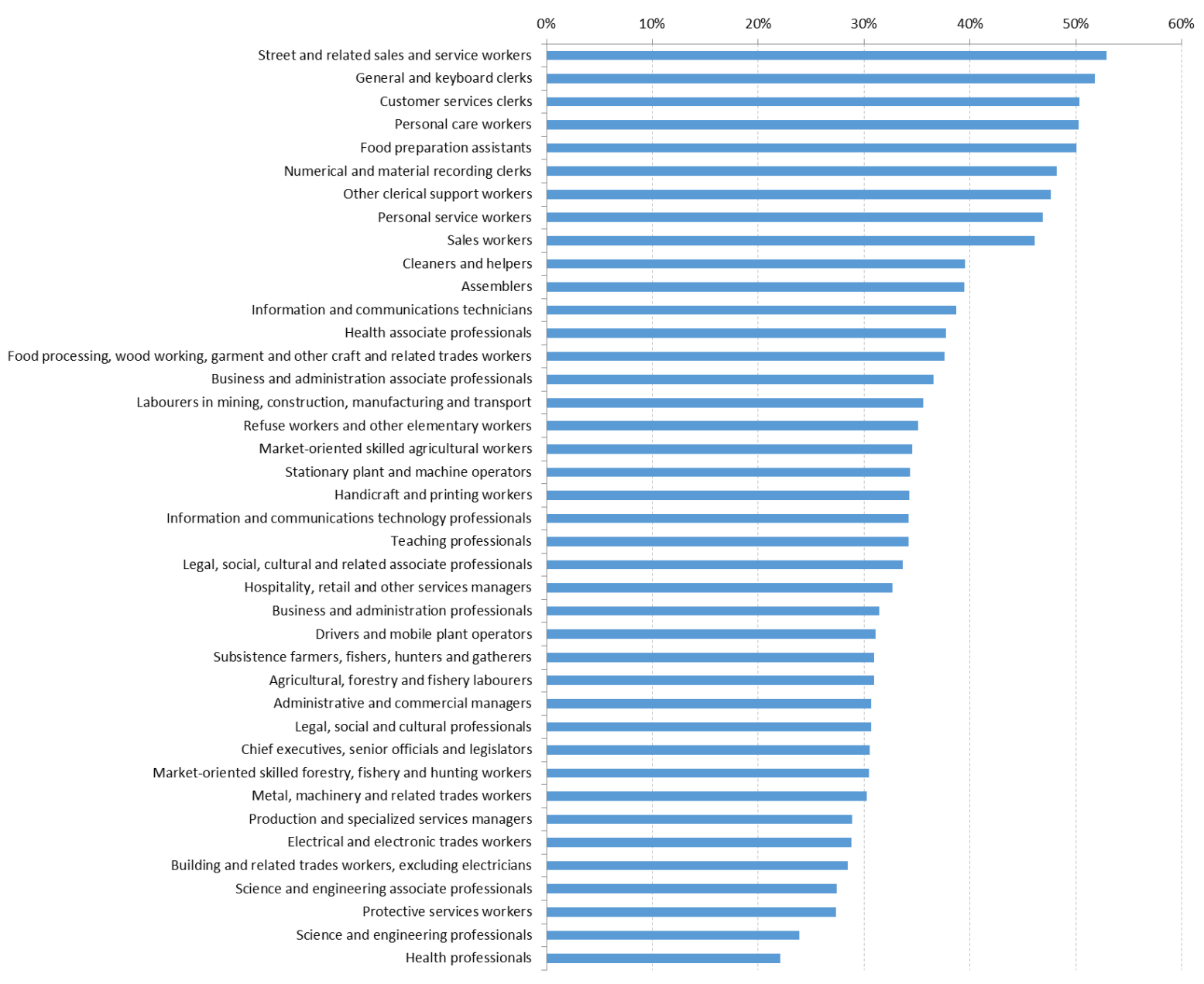

Note: The occupation categories are grouped according to the 2-digit CZ-ISCO codes.

Source: TCCAS.

the capability to retrieve information, gross motor skills, and navigation. The occupations for which these abilities are significant are likely to be under pressure in the near future to replace humans by robotic systems, which will translate into a change in the character of these occupations or a reduction in the number of people required for their performance. On the contrary, in the case of creativity or social and emotional skills, the point at which technologies will reach the level of human ability is still quite distant.

Following the MGI's estimates, three horizons have been set for monitoring the so-called substitutable skills, i.e., skills that will be achieved by technologies at the required level for the occupation, and the so-called irreplaceable skills, where the level required for performing the occupation will not be achieved by the technologies in the given horizon (see Table 2).

\section{Endangered professions}

Given the current state of the technological level in the field of AI, the technology can replace in the next 5 years more than $50 \%$ of the skills required to perform occupations in $11 \%$ of the occupations. The occupations with the highest share of substitutable skills in the shortest timeframe include street sales and service providers, general administrators, secretaries, data entry and text processing 
Fig. 2: Share of substitutable skills in time frame from 6 to 15 years

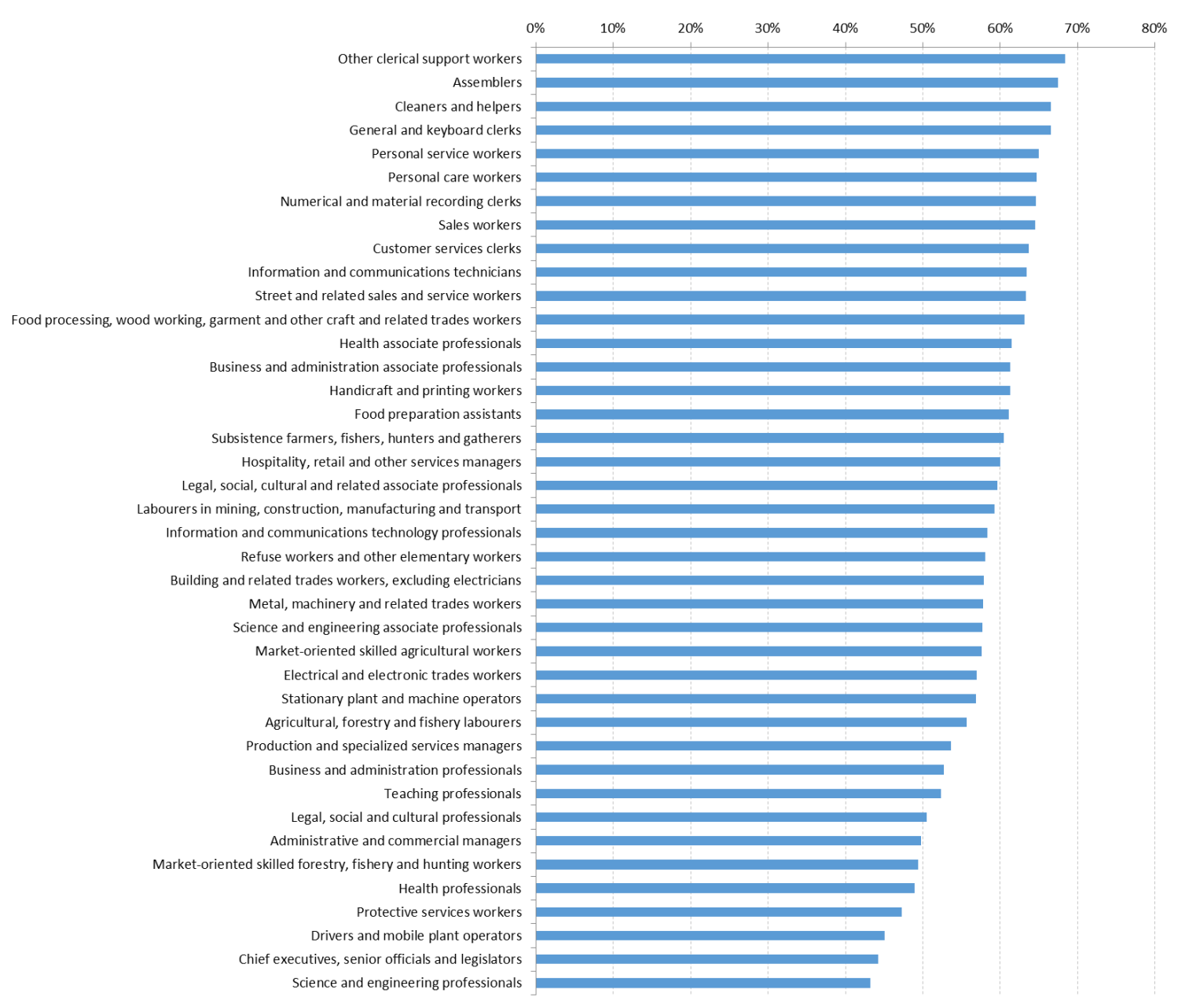

Note: The occupation categories are grouped according to the 2-digit CZ-ISCO codes.

Source: TC CAS.

staff, information services staff, counsellors and associates, personal care workers in education, healthcare and related areas, and helpers in food preparation (see Fig. 1).

It is obvious from the above list that the high potential for skills replacement is not limited to manual occupations. The gradual implementation of technologies into economic activities can affect both manual and administrative jobs associated with data management. On the other hand, the lowest proportion of substitutable skills in the 5-year time frame is found for health professionals, science and engineering professionals, protective services workers, and science and engineering associate professionals.

In the medium term, i.e., within the 6- to 15-year horizon, based on the anticipated technological developments in AI, technology can replace more than $50 \%$ of skills in almost $70 \%$ of the occupations. In particular, development in the field of haptic technology and fine physical motor skills will play a significant role. For this reason, in the medium term, technology can be expected to be able to replace the skills currently needed for the performance of some craftsmen and electronics and electrical workers. A significant share of technology-replaceable skills can be expected in occupations such as clerks, assemblers, cleaners, or general administrative staff (see Fig. 2). 
Fig. 3: Share of substitutable skills in the time frame from 16 to 30 years

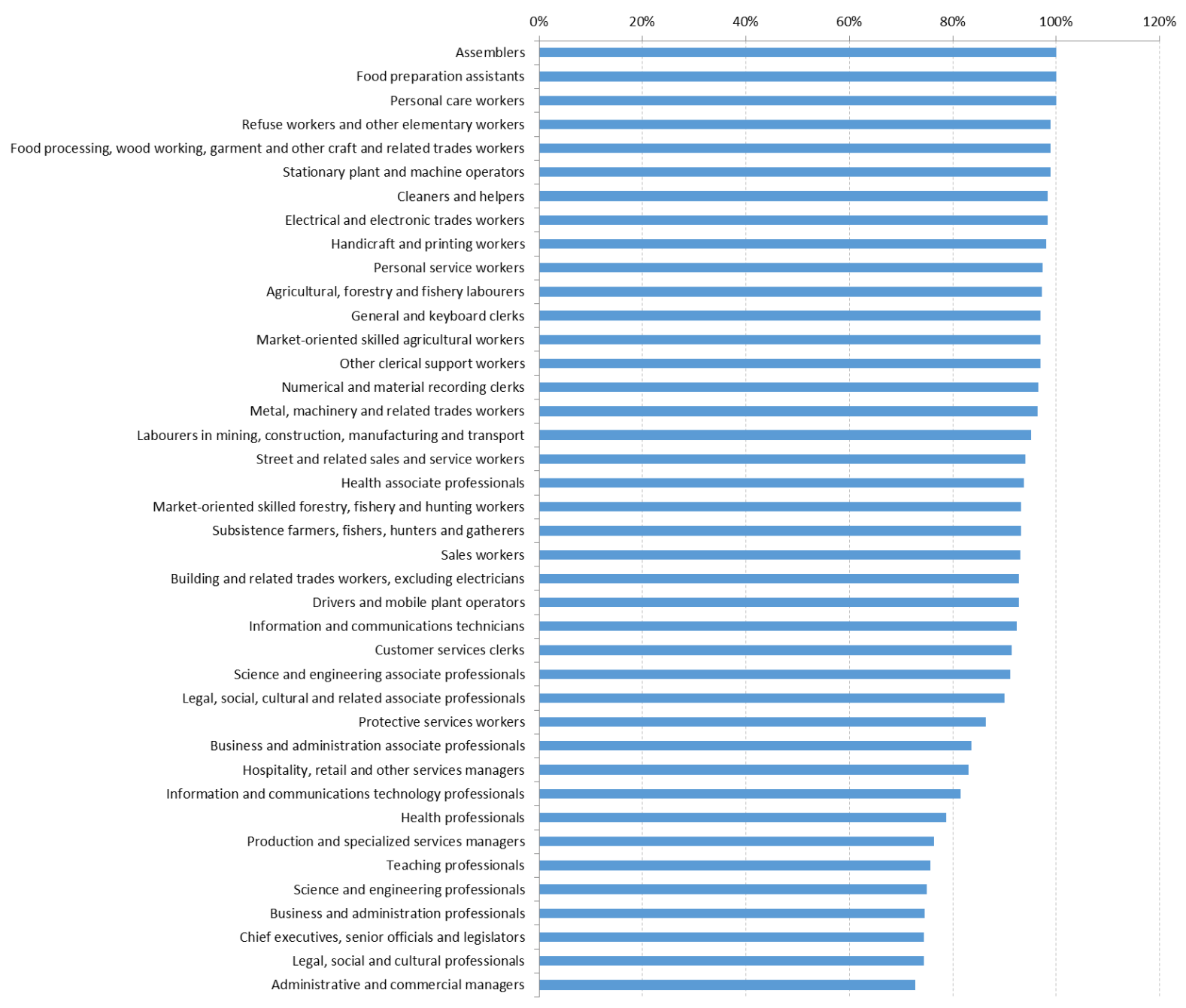

Note: The occupation categories are grouped according to the 2-digit CZ-ISCO codes.

Source: TCCAS.

Looking at a more detailed breakdown, the largest share of replaceable skills will be in the professions related to the clothing and footwear industry. Specifically, it involves sewing and embroidery machine operators, seamstresses, leather processers, or shoemakers. In addition, technologies will be able to replace a significant proportion of the skills required to perform the occupation of fitters, librarians, and also fashion models. On the other side, the smallest share of technology-substitutable skills will have workers who need skills such as creativity, language skills, or social and emotional skills. These professions include, e.g., lawyers, judges, architects, science and technology specialists, meteorologists, and top government officials.

In the long run within the 16- to 30-year horizon, technology can reach a level that more than $50 \%$ of the skills in the vast majority of professions will be replaced. According to our calculations, less than $50 \%$ of skills would only be substitutable for physicists and astronomers. In the other occupational categories, technology will be able to replace most of the skills in the long run, and in $40 \%$ of the occupations all the skills needed to perform these occupations. In particular, the expected technological progress associated with mobility and coordination skills in a multi-actor environment will play a significant role. Occupational groups where complete replacement of human skills by technology may occur are, e.g., assemblers, food preparation assistants, and personal care workers in education, health, and related fields (see Fig. 3). 
A detailed examination of particular occupations shows that for 172 occupational categories (i.e., $40 \%$ of the whole set), all the necessary skills will be substitutable by technologies at the desired level in the long run. Pharmacists, physiotherapists, police officers, or presenters could register the most significant increase in substitutable skills over the medium term. Among the 172 occupational categories with the potential to replace all skills with technology, both manual occupations and white-collar and artistic occupations appear.

\section{Discussion of limitations}

Like any of the classical modes in the literature (see Chapter 2.1), the capability-based model has certain specific limitations that need to be taken into account when formulating conclusions and recommendations for public policy. The first limitation is that the level and significance of occupational competences is based on the current occupation and does not take into account future developments in the nature of the activities carried out in each occupational category and thus the changes in capabilities required for their performance. The second limitation is that the model works with the occupational structure valid at the time of classification (2010). With the development of new technologies, however, new professions arise, either completely new ones or by transforming and modifying already existing professions.

Furthermore, in order to interpret the results in terms of labour market impacts, it should be emphasized that our approach only takes into account one of the factors that determine the potential for the labour automation. In general, we can estimate three basic determinants of the potential for the labour automation. The first is the technical maturity of technologies, which must be able to reach at least the level of skills that people achieve. In addition, there must be a real solution (application) to perform these skills, and the technology must be able to perform these skills reliably. The second factor is the cost-effectiveness, which compares the cost of applying production technology with the cost of labour. Even if there is a real technical solution for applying technology to economic activities, it can be expected in real terms that it will only be deployed once the cost of deployment and operation is lower than cost of labour. The third factor influencing the potential for labour automation is the existence of a functional regulatory framework and the readiness of the society to accept the technology in everyday life. This factor is mainly related to the issue of security and responsibility associated with the introduction of technology, as well as to ethical and moral aspects that determine the society's readiness to accept technology in economic activities instead of people. Achieving a sufficient level of digital literacy throughout society also plays a significant role.

The model takes into account only the first of the above factors determining the potential for labour automation, i.e., technological maturity/readiness. From this we can generally conclude that the time horizons for the real application of technologies in economic activities instead of human labour are likely to be longer than the outlined ones.

\section{CONCLUSION AND POLICY RECOMMENDATION}

Despite the above limitations, the results of the model can give a useful insight into the possible development of skill requirements in the different occupational categories in relation to the trend of automation and the introduction of AI into various economic activities. Based on these estimates, which are also in general accordance with the outputs of the other models presented above, it is possible to generalize the following impacts of AI on the labour market in Czechia (and probably other developed countries).

Occupations with a high proportion of routine skills, either manual (machine operators, packaging and palletizing, dosing) or cognitive (accounting, data collection and processing, text and data proofing, measurement of physical quantities, quality control) are among the professions where the most significant changes in the nature of work due to automation and AI can be expected. The lower risk of human replacement is in professions with a higher proportion of non-routine and creative skills in the manual area (repair and renovation, services and personal care) as well as knowledge area (research, analysis, planning, design, rules and procedures, negotiation and training, leadership, entertainment, and presentation).

Especially professions of middle qualifications and income level are facing a higher risk of replacement. In low-skilled, lowincome manual professions, rather expensive automation is not economically viable in many cases. In high-skilled and high-income professions, however, the automation potential is reduced by the limited availability of the necessary technologies to automate the non-routine and the creative activities associated with these professions. The drop in occupations in the middle-income category 
caused by automation can therefore lead to a deepening of the economic inequality in the society, as mentioned in the study MGI (2017a).

For public policy, this development means an urgent need to focus on addressing related potentially critical issues, especially in the areas of education and social security.

It is necessary to adapt the whole system of education, lifelong learning, and retraining to the changing demands on the skills of the human workforce. The microeconomic data show the increasing importance of the technical expertise (Science, Technology, Engineering, and Mathematics - STEM) and the multidisciplinarity, as mentioned in MGI's (2017a, b) studies. The weight of specialized knowledge is decreasing in favour of the importance of complex skills, especially the so-called $21^{\text {st }}$-century skills (sometimes also referred as so-called soft skills, i.e., skills aimed at developing creativity, critical thinking, collaboration and communication with people as well as machines, presentation, project management, and problem solving), along with the informatics thinking.

Another crucial issue is strengthening social security and developing social safety net. The speed of retraining and finding a new work is different for different employments and employers, which can lead to an increase in the structural and the frictional unemployment, as mentioned in the study MGI (2018). The social safety net must be adapted to this situation to be used to an effective support of the vulnerable employees who seek retraining and expansion of their knowledge, skills, and abilities for the prospective professions. It will be necessary to verify experimentally which forms of support and their combinations will work best for different groups of workers, e.g. reduction of working hours to 30-35 hours per week, the right to the educational leave, the basic unconditional income or early retirement, as mentioned in the IBA's (2017) study.

Automation will change the nature of work and will cause organizational changes in companies. These changes are mentioned in IBA's (2017) and NVF's (2016) studies. Considering the changes in the nature of work, tasks in production and services will be more outsourced to non-core employees. This implies a new demand for the state to ensure social security for a growing number of self-employed people. The importance of suitable self-employment policy for employment in the regions of the Czech Republic is also pointed out by Dvouletý (2017). Instead of a hierarchical structure, companies will prefer a direct and a flexible networking. Greater expectations will be placed on employees in terms of both time and space flexibility of the jobs, which will require a greater flexibility of the wages system. A need will arise to adjust the protection of employees by the labour law. It will include the need to modernize the Labour Code.

The need for an intense development and use of new AI tools puts new demands not only on social and educational policies, but also in the cross-section of general public policies, including structural policies that effectively support entrepreneurship and innovation, competition and regulatory policies, as well as tax policy. Measures reacting to growing international reliance in innovation and knowledge dissemination and measures ensuring adequate assessment of digitalization impact and changes on the labour market are important as well. Beyond this article, these issues are discussed in detail in the study by Fatun et al. (2018).

Almost two years after the elaboration of the model, subsequent studies persistently consider the Czechia as one of the most endangered economies in terms of replacing human work with automation. For example, the study by OECD (2019) states that up to $6 \%$ of workers in Czechia are at acute risk of automation, which is the most of the 31 developed countries compared. However, the current labour market situation is also strongly affected by the COVID-19 crisis, the effects of which will need to be further explored.

\section{REFERENCES}

Bonin, H., Gregory, T., Zierahn, U. (2015): Übertragung der Studie von Frey/Osborne (2013) auf Deutschland. http://ftp.zew.de/pub/zew-docs/ gutachten/Kurzexpertise_BMAS_ZEW2015.pdf

Deloitte (2018): Automatizace práce v ČR - Proč se (ne)bát robotư? https://www2.deloitte.com/content/dam/Deloitte/cz/Documents/ strategy-operations/Automatizace-prace-v-CR.pdf

Dvouletý, O. (2017): Does the Self-employment Policy Reduce Unemployment and Increase Employment? Empirical Evidence from the Czech Regions. Central European Journal of Public Policy, Volume 11,
Issue 2, p. 11-22. DOI: 10.1515/cejpp-2016-0032. https://content.sciendo. com/view/journals/cejpp/11/2/article-p11.xml

European Commission (2018a): Artificial Intelligence for Europe. Communication from the Commission to the European Parliament, the European Council, the Council, the European Economic and Social Committee and the Committee of the Regions. Brussels, 25.4.2018, $\operatorname{COM(2018)} 237$ final. https://ec.europa.eu/digital-single-market/en/ news/communication-artificial-intelligence-europe 
European Commission (2018b): Coordinated Plan on Artificial Intelligence. Communication from the Commission to the European Parliament, the European Council, the Council, the European Economic and Social Committee and the Committee of the Regions. Brussels, 7.12.2018 $\operatorname{COM(2018)} 795$ final. https://ec.europa.eu/digital-singlemarket/en/news/coordinated-plan-artificial-intelligence

Fatun, M., et al. (2018): Analysis of the Development Potential of Artificial Intelligence in the Czech Republic. Summary report written for the Office of the Government of the Czech Republic by a team of authors from the Technology Centre CAS, the Czech Technical University in Prague and the Institute of State and Law of the Czech Academy of Sciences. https://www.vlada.cz/assets/evropske-zalezitosti/aktualne/AISummary-Report.pdf

Frey, C. B., Osborne, M. A. (2013): The future of employment: How susceptible are jobs to computerisation? https://www.oxfordmartin. ox.ac.uk/downloads/academic/The_Future_of_Employment.pdf

IBA Global Employment Institute (2017): Artificial Intelligence and Robotics and Their Impact on the Workplace. https://www.ibanet. org/Article/NewDetail. aspx?ArticleUid=012a3473-007f-4519-827c7da56d7e3509

MGI - McKinsey Global Institute (2017a): A future that works: Automation, employment and productivity. https://www.mckinsey. com/ /media/mckinsey/featured\%2oinsights/Digital\%2oDisruption/ Harnessing\%2oautomation\%2ofor\%20a\%2ofuture\%2othat\%2oworks/ MGI-A-future-that-works-Executive-summary.ashx

MGI - McKinsey Global Institute (2017b): Digitally-enabled automation and artificial intelligence: Shaping the future of work in Europe's digital front-runners. https://www.mckinsey.com/ /media/mckinsey/ featured $\% 2$ oinsights/europe/shaping\%2othe $\%$ 2ofuture $\% 200$ f $\% 20$ work\%2oin\%2oeuropes $\%$ zonine $\%$ zodigital\%2ofront $\%$ zorunner $\% 20$ countries/shaping-the-future-of-work-in-europes-digital-front-runners. $\operatorname{ash} x$

MGI - McKinsey Global Institute (2018): Skill shift - Automation and the future of the workface. https://www.mckinsey.com/ /media/McKinsey/ Featured\%2olnsights/Future\%200f\%20Organizations/Skill\%20 shift $\% 20$ Automation\%2oand\%2othe\%2ofuture\%20of\% $\%$ othe $\% 20$ workforce/MGI-Skill-Shift-Automation-and-future-of-the-workforceMay-2018.ashx

MPO - Ministry of Industry and Trade of the Czech Republic (2019): National Artificial Intelligence Strategy of the Czech Republic. https:// www.mpo.cz/assets/en/guidepost/for-the-media/press-releases/2019/5/ NAIS_eng_web.pdf

NVF - National Training Fund (2016): Iniciativa Práce 4.0. Ministry of Labour and Social Affairs. https://portal.mpsv.cz/sz/politikazamest/ prace_4_o/studie_iniciativa_prace_4.o.pdf
OECD (2016): The Risk of Automation for Jobs in OECD Countries. OECD Social, Employment and Migration Working Papers No. 189. http:// www.ifuturo.org/sites/default/files/docs/automation.pdf

OECD (2018): Achieving inclusive growth in the face of digital transformation and the future work. https://www.oecd.org/g20/OECD_ Achieving\%2oinclusive\%2ogrowth\%2oin\%2othe\%2oface\%20of\%20 FoW.pdf

OECD (2019a), Artificial Intelligence in Society, OECD Publishing, Paris. https://doi.org/10.1787/eedfee77-en

OECD (2019b): OECD Skills Outlook 2019: Thriving in a Digital World, OECD Publishing, Paris. https://doi.org/10.1787/df8obc12-en

OSTEU - Department of Strategy and Trends of the European Union (2015): Dopady digitalizace na trh práce v ČR a EU. OSTEU Discussion paper 12/2015. Office of the Government of the Czech Republic. https://www.vlada.cz/assets/evropske-zalezitosti/analyzy-EU/Dopadydigitalizace-na-trh-prace-CR-a-EU.pdf

PwC (2018): Will robots really steal our jobs? An international analysis of the potential long term impact of automation. https://www.pwc.com/ hu/hu/kiadvanyok/assets/pdf/impact_of_automation_on_jobs.pdf 